\title{
Culture and Mental Health Counseling: A Reflective View Based on Observations in China
}

\author{
By Changming Duan*
}

\begin{abstract}
Western initiated internationalization of professional psychology has resulted in mental health counseling, a profession indigenous to the Euro-American culture, being transplanted in different parts of the world. Questioning the cultural appropriateness of applying Western theories in non-Western cultures has become more and more imperative and urgent. This article reflects on the cultural context of Western professional counseling and its internationalization and discusses possible harm and problems of practicing Western mental health counseling internationally. Based on observations of counseling development and research in China, the argument is made that lack of attention to the role of culture leads to harm. All professionals who are interested in being part of this internationalization movement need to adopt an international attitude, conduct sharing and learning through a dual-directional collaborative pathway and show a commitment to doing courageous work in de-constructing and re-constructing the science and practice of professional psychology for the global community. Only with proper and sufficient culturally informed effort, internationalization of mental health counseling can result in mutual enrichment and benefit all people in all cultures.
\end{abstract}

Keywords: culture, mental health, counseling, internationalization, China

In the last few decades, one of the significant developments in the field of psychology and mental health has been internationalization of mental health counseling, an indigenous European-American cultural product (Christopher et al. 2014). Increasingly, scholars and practitioners from selected Western countries developed an "on-going commitment to and involvement in the international arena" (Casas et al. 2010: 191). This trend is inevitable in the context of modern globalization (Friedman 2006), and reflects the interest and motivation of the Western professionals to make professional psychology international. While many parts of the world have generally embraced Western psychology and counseling, with or without choice or deliberate intention, there have been reasons and observations that call for responsible and serious reflections about how this internationalization movement has influenced individuals, families and communities around the world. Such reflections may lead to reconsideration of how internationalization should be defined, conducted and promoted so it can reach the desired goal of benefiting but not harming those we intent to help.

In this paper, I briefly describe the cultural context of Western mental health counseling and discuss the possible lack of cultural fit when it is practiced in nonWestern cultures. Based on my limited understanding and observations, I share what I see as problematic and reflect on what is needed to put corrective effort forward and prevent further harm. Internationalization will continue and deliberate

"Professor, University of Kansas, USA. 
efforts are needed to make it a great movement benefiting the entire global village. For the sake of convenience, I used the term West or Western to group the United States and some parts of Europe where there is a shared history of psychology discipline development.

This paper unavoidably contains my personal biases as a China-to-U.S. immigrant whose perspectives have been shaped by life experiences both in China and in the United States. I grew up in China, and have received graduate training, lived and worked in the United States. On a continuous basis, I am engaged in collaboration with Chinese scholars in mental health counseling research and training in China. My general, perhaps biased, conviction is that while the globe is gradually flattening (Friedman 2006) in economics and other areas, the diversity of culture remains a beauty of the world and mental health a culture-driven phenomenon. Thus, I plea to our academic and professional community that significant attention be given to the role of culture in everything we do to promote mental health, and please recognize that failure of doing so is harm to non-Western individuals and societies that constitute a large part of the world.

\section{Cultural Contexts of Mental Health Counseling Development and Internationalization}

It is probably not accidental that mental health counseling along with its parenting scientific discipline, psychology, started in only a few small areas of the globe (West Europe and North America) and among a small portion of the world population, namely, the Western, Educated, Industrialized, Rich, and Democratic (WEIRD; Henrich et al. 2010). Nor is it arbitrary that the principles and ideologies reflected in the professional counseling, as we know it today, are mostly consistent with those rooted in individualism (Baumerister 1987) that dominates EuroAmerican cultures (Hofstede, 2001) and are highly valued among the WEIRD. As these cultures promote individual rights, autonomy and independence, and free choice, mental health counseling logically and conveniently emphasizes selfunderstanding, self-identity, self-actualization, freedom, individual happiness, and so on. As noted, the development of mental health counseling or psychotherapy has been viewed "a clear American tale of discovery, entrepreneurship, and selfpromotion" (Engel 2008: xiv).

Culture is the foundation of human behavior and it shapes personalities (Triandis and Suh 2002) and permeates human existence (Geertz 1973). However, there has been empirical effort, based on biology or by "cross-cultural" studies that treat culture as a nuisance demographic variable, to show that a universal human nature or certain personality factors are cross culturally valid (Vogt and Laher 2009). This is not surprising given "the entrenched parochialism and ethnocentrism" (Christopher et al. 2014: 645) of Western psychology and publishable research being known to reflect "psychology that is incomplete and does not adequately represent humanity" (Arnett 2008). In fact, even the "significant" result supporting universality does not nullify the role of culture in human nature. 
From a hermeneutic perspective, studying Western personality constructs among individuals in other cultures where "self and culture are inextricably linked" (Christopher et al. 2014: 650) would require a lot more than what published studies usually do (examining the individuals without attending to the inseparable part of them: culture). Using Western scientific method studying Western psychological constructs (many of which are meaningless to people outside of Western countries and even not translatable to non-English languages) for understanding people in culture is fundamentally problematic because of its inability of observing "shared meanings and their import for subjectivity and social relations," (Christopher et al. 2014: 653) which is part of the self of those people. From another angle, an evolutionary psychological perspective, it is more likely than not that culture selectively activates complex psychological mechanisms in human mind (Buss 2001) even if the biology is the same. Moreover, using available empirical evidence to argue for universality is problematic because "most studies have not included emic (culture-specific) traits and have not studied samples that are extremely different in culture from Western samples" (Triandis and Suh 2002: 133).

It is apparent that the narrow cultural focus of psychology, unrepresentative of the majority of cultures worldwide, led to a culturally exclusive psychological knowledge base that is difficult for international application due to lack of cultural fit. Nonetheless, the past few decades have witnessed mental health counseling in theoretical and practical packages being transported from the West to many parts of the world regardless of local cultures. The privilege of circulating cultural products in a culturally neutral manner certainly belongs to Western professionals and shapes the development of psychology in the international arena.

The push from the West to popularize psychology and mental health counseling in China occurred in late 1980s as the world globalization was marked by new progresses (Boughton 2002) and when China embarked on its economic reform following the "Open Door" policy issued in 1978. This Open Door action opened not only China's economic market but also its people's mind toward the West and interest in Western cultural and intellectual products. At the time when mental health counseling as a profession had matured in European and North American countries, the idea of expanding its influence and disseminating its products seemed natural, timely and appealing. Thus, a gradual movement transpired in the West to introduce professional counseling to other countries (Norsworthy et al. 2009).

As the result, under the name of "internationalization," and sometimes accompanied by the label of "indigenization," counseling theories and systems entered China from the United States and some European countries, along with devoted scholars and practitioners who generously offered their time and expertise to training Chinese practitioners. Having little non-medical professional mental health care at the time (Qian et al. 2002), China eagerly accepted the newly imported theories and systems. For instance, psychoanalysis, in its rather traditional form, became a hot and attractive area quickly, and caused high "folk fever" among professionals and the public (Jia 2016: 379). With the persistent effort from several groups of psychoanalysts from Germany, United States and 
Norway, China let "Freudians put China on the couch" (Tatlow 2010) just in a few short years. It is quite provocative for us to witness the increasing popularity of Western imported psychoanalysis in China during the time when the medical historian Jonathan Engel (2008) noted "Psychoanalysis has largely died" (p. x) in the United States and the president of American Psychoanalytic Association Dr. Warren Procci acknowledged, in 2010, that "There is an unavoidable message here, much as we do not want to hear it ... We are in a decline" (cited in Osnos 2011: 56). In significant ways, psychoanalysis defined mental health for the Chinese yet-to-be-developed mental health care system. Its large influence filled the center of the professional space and attention, and entered the public's initial knowing about mental health and counseling. Quickly, the Chinese mental health counseling market became heavily psychoanalytic/psychodynamic, and other therapeutic approaches had a harder time to gain as much public acceptance and recognition as quickly.

\section{Addressing the Issue of Cultural Fit: Optional or Imperative?}

While such Western enthusiasm and assistance helped jump start professional counseling in China at a time when the globalization and China's opening door to the world unavoidably brought new mental challenges to its citizens, the issue of cultural fit started troubling the academic community and intensified over time. However, due to being largely in a powerless recipient status (without existing counseling professional literature or system) and perceived as suffering from significant increase of mental illness due to the economic reform (Yan 1998), China was not in a position or had the resource to scrutinize or examine those Western imports for cultural relevance. Therefore, the mental health counseling field took shape and developed with mostly Western features and styles, from its operation to its intervention strategies. Mainly translated textbooks and materials from English were used for teaching and training.

One area in which cultures differ is the degree to which individualism and collectivism predict human behavior and emotions (Hofstede 2001). There has been a significant amount of empirical evidence showing that some countries are more or less individualist or collectivist than others, with the United States topping the list of the most individualist countries (http://www.clearlycultural.com/geerthofstede-cultural-dimensions/individualism/). Viewing humans as cultural beings, Triandis and Suh (2002: 907) summarized years of research and unambiguously stated "People in collectivist cultures, compared to people in individualist cultures, are likely to define themselves as aspects of groups, to give priority to in-group goals, to focus on context more than the content in making attributions and in communicating, to pay less attention to internal than to external processes as determinants of social behavior, to define most relationships with ingroup members as communal, to make more situational attributions, and tend to be selfeffacing." This is a good description of the psyche of people from most nonWestern cultures. Thus, questioning the cultural fit of Western theories in these cultures is imperative. 
There has been research examining mental health related concepts as associated with individualism and collectivism. By comparing mental health stigma among several different ethnic groups in UK, Papadopoulos et al. (2012: 270) revealed that, "the more stigmatizing a culture's mental illness attitudes are, the more likely collectivism effectively explains these attitudes. . . the more positive a culture's mental illness attitudes, the more likely individualism effectively explains attitudes." These findings are not surprising considering the nature of individualism and collectivism, but what is interesting and provocative is that such findings are often taken as denoting something negative about collectivism in terms of mental health care. The Westernized thinking is that stigma is an obstacle for promoting interventions and therefore should be reduced or eliminated. Rarely researchers have openly reflected on the possibility that findings like these indicate how mental health is defined, mental illness identified, and mental health care provided are inappropriate in collectivism dominant cultures.

Lack of attention to the role of culture is reflected in even social-justiceoriented and assistance-focused efforts addressing negative stigma against the mentally ill. Issues of ignorance, prejudice and discrimination embedded in the stigma were brought to the front (Thornicroft et al. 2008), but questions concerning who are the targets of the stigma and how they became the target were not asked. As expected, existing stigma intervention theories often lack crosscultural effectiveness (Yang 2007). Unfortunately, the way in which mental illness is defined and stigma viewed is almost universally accepted due to evidence generated by Western trained or Western theory influenced stigma researchers. The scholarship in this area implies that higher stigma is a sign of weakness and more deliberate intervention is needed (Link and Phelan 2001), and fails to acknowledge cultural biases in the definition of mental illness in the first place.

Cultures vary in how they view un-conventional or un-normal behavior. The U.S. based Diagnostic and Statistical Manual of Mental Disorders, a creation of American Psychiatric Association, demonstrated a high tendency to pathologize behaviors. From the first to the fifth edition, it grew from 129 pages containing 106 diagnoses in 1952 to 950 pages with roughly 375 diagnoses in 2013. However, when DSM diagnostic criteria consistent behaviors were presented to Chinese, most people would not label them as being symptoms of illness. Rather, they would see the "symptoms" as evidence of "taking things too hard" or "being stuck in thinking" ( $\mathrm{Li}$ 2015). This phenomenon is conveniently labeled by Western standards as lack of "mental health literacy" (Jorm 2012), the connotation of which is unambiguous. Clearly, emphasis on labeling mental illness is culturally determined but the culture-neutral stance or cultural inaptness of Western research has portrayed non-Western countries as being lagged behind or under developed in removing stigma toward mental illness, which is culturally insensitive, improper, and possibly damaging. 


\section{Mental Health Counseling as an Internationalized Profession}

Gradually and surely, mental health counseling has become an international phenomenon. While the Western internationalization has contributed to development of the profession in many parts of the world, a critical view has always existed regarding the one-directional nature of such international effort and its unintended negative consequences (Duan and Goodyear 2015). However, this concerning view has not made any significant wave under the impetus for showing generosity in helping the needed. In his thought provoking and influential book Crazy like us: The globalization of American Psyche, Watters (2010: 254) documented several ways in which the best-intentioned helping efforts by American mental health professionals disseminated the "American brand of hyperintrospection and hyperindividualism" and supported "the grand project of Americanizing the world's understanding of the human mind" (Watters 2010: 1).

Using narrated country specific case examples, Watters detailed how psychopathology or mental illness, defined by the West, was introduced and passed on to different countries. As a result, anorexia nervosa that used to be an exclusive Western eating disorder (Swartz 1985) became prevalent in Hong Kong through the promotion of Western thinking concerning healthy/unhealthy eating behavior, and by popularizing diagnostic labels, illness-focused prevention and intervention strategies to reinforce the notion of eating disorder. Through a different route, "Americanized version of depression" (Watters 2010: 2), along with corresponding SSRIs (Selective Serotonin Reuptake Inhibitors), was introduced and imposed to Japanese after the targeted "educational" campaign by American drug companies with involvement of credible psychiatry experts. Japanese were educated by Westerners to change their negative attitude toward depression, which marked the beginning of the current state of affair that increasingly more people became depressed and depression was medicalized (Kitanaka 2006). Packaged with the post-crisis assistance, PTSD (Post Traumatic Stress Disorder), an American socio-political specific label for a particular group of veterans at a particular point in time, was brought to Sri Lanka after 2004 Indian Ocean tsunami by well-intentioned U.S. professionals. Operating out of their own knowledge base, experts introduced PTSD symptoms as must-be-present after natural disasters and taught the locals how to think or feel as victims. The gross cultural inappropriateness was "disappointing and sometimes shocking" (Ganesan 2006: 360) to local professionals and created- negative consequences with real people being harmed (Christopher et al. 2014).

From one angle, these cases illustrated how one-directional internationalization could result in exporting Western mental illness and its interventions, which has caused harm in various cultures. Undoubtedly, such potential harm was unintentional, but unintentional harm is harm and should not be brushed over. In the counseling profession anywhere nowadays, Western knowledge is clearly privileged and local scholarship and healing practices discouraged or refuted. One major reason is due to the power structure, where scholars from the Western countries run premier scholarly journals and host prestigious academic and professional conferences; Western universities train world's most influential 
academics and clinicians; Western generous volunteers have the resource to engage in world crisis interventions; Western medical models (implicit but prevalent in counseling) enjoy world-wide recognition and acceptance; Western drug companies spend big money promoting psychotropic medications everywhere; and so on. The values embedded in most currently available counseling systems and assumptions about how human mind works are representative of those by the WEIRD populations rather exclusively. From top or powerful positions, Western professionals can easily apply their knowledge as universally helpful and offer assistance accordingly, which in turn helps maintain the Western position of power.

\section{Culture-bound Nature of Mental Health: A Comparison between U.S. and China}

Both anecdotal and empirical observations in China support the argument that mental health is a culture-bound concept, and harm is really possible when it is viewed in a cultural vacuum. Facing the reality that Western counseling theories and practices have gained acceptance and popularity among mental health providers, it is time for researchers, practitioners and consumers as well as the governmental agencies to ask serious questions concerning the consequences of such practice. Fortunately, conversations on issues related to cultural fit of imported counseling theories and methods have started (Jia and Zen 2014). There have also been empirical studies examining cultural characteristics of Chinese mental health, mental illness, therapeutic interventions and healing arts, which will enrich the understanding of ways to enhance mental health in China.

In the United States, goals of mental health counseling reflect the mega theme of individualism, namely, "helping individuals to overcome obstacles to their personal growth, whereever these may be encountered, and toward achieving optimum development of their personal resources" (American Psychological Association 1956: 283). The markers of mental health include adequate selfunderstanding or insight, self-identity, self-realization, autonomy, freedom, choice, independence, individual happiness, no negative emotions, etc. The focus on the individual and individual rights and interest is in the center of these definitions. The well-known existential theorist and psychotherapist Rollo May reflected toward the end of his life:

"... we in America have become a society devoted to the individual self. The danger is that psychotherapy becomes a self-concern, fitting what has recently been called a new kind of client, the narcissistic personality. . . . we have made of therapy a new cult, a method in which we hire someone to act as a guide to our success and happiness. Rarely does one speak of duty to one's society - almost everyone undergoing therapy is concerned with individual gain, and the psychotherapist is hired to assist in this endeavor "(May 1992: $\mathrm{xxv}$ ) 
In sharp contrast, China defines the goals of mental health services as "to improve public mental health, promote social stability and interpersonal harmony, and enhance public well-being, ... and to cultivate good morality, promote coordinated economic and social development, nurture and exercise socialist values and principles" (Committee of National Health and Family Planning 2016: 1). The central focus is on stability, harmony, public well-being, and morality to ensure economic and social development. These goals differ from those cherished by most mental health counseling theories in 1) emphasizing public health, 2) promoting harmony, which has to involve others or society, and 3) stressing morality and social responsibility.

The different views of mental health reflect different cultural values, particularly those values concerning the individual and self. There have been theories differentiating individual, collective and relational self (Sedikides and Brewer 2001) and independent and dependent self (Markus and Kitayama 1991). Theorists tend to view these various selves co-existing in individuals, but recognize the patterns of experienced self in cultures (Oyserman and Lee 2008, Sedikides et al. 2011). It is not hard to derive the general understanding from a myriad of theories and research findings that the independent self and individual self are more salient than relational, collective, or dependent self for individuals from the West (more individualist than collectivist culture) and the vice versa for those from the East (more collectivist than individualist culture).

Having different types of self is no small matter in terms of how mental health should be understood and cared for. The China's definition of mental health does reflect collectivist nature of the culture, where "we" or "our" mentality (collective, dependent and relational self) is much more prominent than "I" or "my" focus (individual and independent self). For instance, people are much more like to use "our" than "my" in daily language, such as "our country" (vs. "my country)." Interestingly, "country" in Chinese is 国家 containing both "state" (国, guo) and "home" (家, jia). In the traditional view, Chinese value "One should be the first to worry for the future of the state and the last to claim his share of happiness" (先天下之忧而忧，后天下之乐而乐) (From Poem by范仲淹 Song Dynasty ${ }^{1}$; Researchers have described basic Chinese values in modern time as respect for age, group orientation, concept of face, and importance of relationships (Lockett 1988), or that for family or kinship, elders, obligations toward friends and relatives, and harmony and face (Tan 1990).

Arguably, Chinese culture has been changing and adjusting in the context of being a member of the globalized world (Liu 2012), but distinct cultural characteristics remain. A study of mental health values among college students revealed several traditional cultural tenets in how mental health is viewed (Lei 2016). After running several focus groups, interviews, and a survey of a large number of students, Lei found six themes of their mental health values: functionality in contexts, family, relationship, character and attitude, purpose and meaning, achievement and communication. These themes contrast those used to measure mental health values in the United States: self-acceptance, negative traits,

\footnotetext{
${ }^{1}$ Retrieved from https://zhidao.baidu.com/question/490725319040991852.html.
} 
achievement, affective control, good interpersonal relations, untrustworthiness, religious commitment and receptivity to unconventional experiences (Tyler et al. 1983). Chinese students' values seem to be more collectivist than individualist and more other-focused than self-focused. In her report, Lei particularly emphasized that throughout her research process, family and relationship arose as top considerations among the participants whenever they thought about mental health.

There have also been limited discussions and empirical explorations on cultural variations regarding mental illness and its diagnosis, which demonstrates researchers' attention to the importance of culture. Nonetheless, DSM still becomes a widely used diagnostic bible all over the world and mental illness is talked about linguistically as a universal concept. Notably, a recent study in China produced evidence to question this practice. Using a large sample drawn from multiple provinces and representative of a wide range of age and educational levels, Li (2015) examined the public's view of mental illness. The result showed that Chinese public lacked a clear concept of mental illness/disorder (not seeing certain DSM symptoms as expression of mental illness), focused on consequence/ impact when led to think about mental illness, emphasized multi-factors if asked to make attributions, and recognized both the role of individual subjective willpower and that of social/family support when talking about healing from mental illness. In contrast, studies in the United States had demonstrated a strong public concept of mental illness, high stigma toward those who are mentally ill in society; strong focus on causes and biomedical interpretations in discussing mental illness; and enthusiasm in advocating for professional care (Martin et al. 2007). Evidently, Westerners endorsed more of a medical view and made stronger call for professional interventions than Chinese, and Chinese were less likely to see atypical behaviors as expression of illness and more concerned with consequences of those behaviors than Westerners.

Observable in clinical settings, Western beliefs about psychological trauma (how it occurs and recovers), necessity of venting emotions for recovery (seen as healthier than stoic silence), human fragility and mental illness, biomedical approach to understanding and treating mental illness have shaped treatment of mental illness all over the world. In my many conversations with and supervision of Chinese counselors, I have observed that they tried very hard to apply the "right" intervention, even if they feel it being counterintuitive and lacking cultural fit. For instance, once in a supervision group when one relatively unexperienced member reported that her male college student client, who came to counseling for lack of motivation to study, reported feeling better after two "supportive" sessions, several more experienced counselors in the group expressed doubt about the progress and deemed the client being in denial. They believed that he couldn't have really felt better because he had not developed deep understanding of the trauma his strict mother (Client said that his mother was strict and would ban him from playing when he received bad grade) had caused him, got in touch with and express his inner anger toward mother, and experienced transference with the counselor to fully express his anger toward mother in session. I was in absolute disbelief, seeing the degree to which the Western psychoanalytic thinking 
compromises local clinician's sense of cultural reality. It is alarming knowing that prior to counseling being internationalized, "Nowhere else in the world do people explore their deepest and most intimate secrets with total strangers with such alacrity and enthusiasm" (Engel 2008: xiv).

Culture shapes mental health, mental illness, its diagnosis and its treatment (Watters 2010), it would be irresponsible and unethical if we do not ask serious questions concerning efficacy or harm of existing mental health practice. Equally important that local cultural practice be revealed and understood. In this spirit, a series of counseling process and outcome studies in China were conducted and demonstrated that Chinese clients' help seeking behavior (Xia et al. 2015), counseling expectations (Duan et al. 2011), preferred interventions (Duan et al. 2014), as well as coping and change processes (Lei and Duan 2015) were often different from those commonly believed and observed in the Western countries. For example, Xia, Jiang and Duan found that one of the most important determinants of professional help seeking among college students was client selfefficacy of being a good client. Students would not seek help if they do not believe they can be good clients, which hasn't been much of a topic in Western literature.

The research on use and effect of counselor directives (Duan et al. 2012, Duan et al. 2014, Jiang et al. 2017) showed that both counselors and clients expect counselor directives (counselor telling client what to do) as it is culturally appropriate for a hierarchical relationship like that between counselor and client. Counselors do in fact often use directives but a) want to hide the fact that they used them, knowing they "shouldn't" based on their training, b) want to deliver the directives indirectly, so clients won't lose face, c) evaluate non-directive counselor behavior higher than that of directive counselors, knowing that is what theories say, and d) prefer directives that "plant a seed" or are "encouraging" than those that give solutions. On the other hand, clients reported wanting to have counselor directives, receiving more directives than their counselors said they had given (deriving them from counselor comments), feeling better (more hopeful, thoughtful, and relieved) after receiving directives (before or without implementation) and only intending to implement the directives if they are beneficial and doable. These results make sense in the context of Chinese culture, but are not typical from the perspective of established theories.

\section{Reflective Comments}

Internationalization of mental health counseling should and will continue. With proper culturally informed effort it will benefit all people in all cultures. There are significant challenges, however. First, although the existence of cultural diversity has been generally acknowledged, the danger of its absence in mental health counseling has not generated due attention. Sufficient awareness is yet to be achieved that psychology and established mental health counseling are indigenous to the Euro-American culture, and without proper de-constriction and reconstruction, transplanting it to other cultures runs the risk of being culturally colonizing (Adams et al. 2012), homogenizing (Melluish 2014), and even 
exploitation (Jagger 2002). Further, the one-directional internationalization from the West to developing countries or the "global south" during the time of their economic and social vulnerability has created large markets for Western imported counseling systems and inadvertently marginalized local professionals and local folk psychologies. American "definitions and treatments" of mental illness "have become the international standards" (Watters 2010: 2), which gives more power to Western exporters and more urgency to locals to import what is offered by the West. The language barrier also contributes to the existing power structure by using English in the world's understanding of mental health. While students of psychology in many non-English speaking countries have full access to English literature, most English-only speaking professionals may have limited knowledge about the countries where they are offering help. Much of the research outcome from non-English speaking countries has not been integrated in the knowledge of the profession.

Actively pursuing an international agenda is on the right side of history, but making this course mutually beneficial requires deliberate, intentional and wellthought equal-power collaborations among all who are involved. There are proposed models and methods such as emic-and-etic integrative approach (Cheung et al. 2011) or cultural lens approach (Hardin et al. 2014) that are appropriate for international work, but acquiring international and multicultural competence should the preamble for involved professionals. Individuals who are to conduct international work need to position themselves with an appropriate attitude and clear direction as well as a commitment to doing the necessary learning before embarking on the task.

\section{An International Attitude}

An international attitude involves a new worldview that acknowledges the uneven distribution of power, a new understanding of how this power structure shapes human experience in international communities, and a new commitment to dismantling this power structure for the sake of being truly humanitarian and generating mutual benefit. Further this attitude contains a view seeing all international work as a mutual learning process, because there are no experts when the knowledge changes cultural settings. It falls on the shoulders of the powerful to be willing to share power, adopt a learning mindset, and respect equal partnership. The less powerful should recognize their power on other scales such as the knowledge of local culture, being in a relatively more relational context, and having access to local resources. Each side has advantages and disadvantages and has the responsibility to share with and learn from the other. This has to be a deliberate and intentional process in which both offerors and receivers cultivate a critical cultural awareness and initiate examinations of cultural fit for everything that is transported.

In clinical settings, an international attitude allows us to see that culture defines mental health and constructs clinical reality (Kleinman et al. 2006), and any ethnocentric view of mental health is harmful to others in different cultural 
reality (Comas-Diaz 2011). It is a sobering fact that the current body of psychological knowledge is largely grounded in mono-cultural perspectives that promote Euro-American ethnocentrism, because it was "created by the mainstream to serve the mainstream... has failed marginalized people in fundamental ways" (McLellan 1999: 325).

Internationalization should not be "the 'Americanization' or 'Westernization' wrapped around on the outside by a nice wrapping paper with an 'international' label" and instead, should be "an ongoing process of integrating knowledge from research and practice derived from different cultures and applying this knowledge to solve problems in local and global communities" (Leung et al. 2009: 112) and involves "collaborations and equal partnerships in which cultural sensitivity and respect are required for success" (p. 115). An ethnocentric view would make Western professionals of mental health counseling feel being in an "advanced" position and having little to learn from other countries. An international attitude, however, would enable them to see the actual reality that Western professionals do not know as much as those from other countries about folk psychologies, different worldviews and diverse moral visions (Christopher et al, 2014), the very foundations of mental health. As pointed out by Moghaddam et al. (2007: 181), alternative psychologies by the third world countries have more advanced abilities to generate locally relevant knowledge and "achieve greater contextual sensitivity to address the diverse needs of continually changing societies." Moreover, there has been cultural wisdom around the world that U.S. or other Western countries could benefit from. For instance, understanding meaning of suffering, mindfulness practice, or lighting a lamp for someone else as means to brighten one's own path, to name a few, from Eastern cultural or Buddhism traditions can potentially help even the WEIRD at times.

\section{A Dual-Directional Communicative Path}

Building two-way streets in all international work is necessary and constructive, and learning and sharing should always go hand in hand for all who are involved. Quite often professionals from the West are automatically seen as teachers or experts when working in other countries, which could make it difficult for them to engage in knowing and learning what they lack while sharing what they know. Scholars have pointed out that Western professionals may not be aware of the weakness in their knowledge and skills when cross-cultural work is attempted. These areas include insufficient understanding of the "cultural grounding of human experience and social relation" (Christopher et al. 2014: 652), weak tools and skills to "discern folk psychologies and moral visions that differ from their own", and others. A deliberately designed two-way street with collaborative partnerships will allow necessary mutual learning to avoid harm inherit in one-directional sharing and maximize the benefit of dual directional assistance and enrichment.

There are wisdom to be gained and lessons to be learned in both directions. It has been well recognized that the mental health counseling profession in the West 
has a lot to be internationalized, and the rest of the world has been trying to "catch up" by learning as much as possible from the West. Little effort has been made to bring awareness that many non-Western countries have a lot offer as well, in areas such as understanding folk psychologies, healing people in relationships, holistic philosophy in health care, prevention via prioritizing public health, Eastern religious teachings related to psychological peace and harmony, and so on. Further, there are also various cultural practices around the world that are effective in non-professional interventions aiming at coping, relaxation, and maintaining well-being. A good example is that mindfulness and meditation from the Eastern tradition have been widely accepted and proved to be efficacious in psychological healing and well-being for people cross country and culture boundaries. Lack of intentional learning from other cultures is failure to use resource, which hinders progress and development of a healthy discipline or profession.

\section{An Agenda of Courageous Effort}

It takes courage to do the needed self-work before, during and after reaching out internationally for Western professionals, because this work involves recognizing serious limitations and blind spots, as well as the ethnocentrism embedded, in the knowledge that was generated mainly by and for the WEIRD populations. Willingness to see the possible harm of directly applying this knowledge in different cultures is necessary. Specifically, answering the call for decolonizing psychological science (Adams et al. 2012) and critically examining the knowledge that is being disseminated require courage to challenge, to selfexam and to adopt different perspectives. Liberation Psychology that addresses privilege-power dynamic and Cultural Psychology that emphasizes the interplay of culture and mind (Shweder 1990) are good resources for learning. Getting out of the comfort zone and seriously considering de-construction and re-construction of what has been established are necessary to meet the challenge of the $21^{\text {st }}$ century (Marsella 1998). Further, it is important that one takes an emic perspective in understanding any culture, and prioritizes achieving cultural fit. Being fluent in a specific foreign culture is challenging but necessary, and it is impossible for anyone to be an "expert" without being fluent in the culture and understanding the construction of the cultural reality.

On the side of the professionals from non-Western cultures, it also takes courage to show responsibility learning what is being offered, asking serious questions concerning its cultural fit, and offering local cultural understanding to assist the necessary deconstruction and reconstruction processes. It is always challenging to speak up to the powerful when being on the bottom of the power totem. What may be helpful is the knowledge that no one knows particular cultural contexts better than those who live in the culture. The similar logic applies that mental health professionals within the culture have the unremitting responsibility to prevent harmful imports that lack cultural fit. In fact, Western professionals are generally interested in learning new cultures and respect those who can think critically and challenge existing knowledge, which is a practice Western scientific 
community values. They need assistance from the local professionals to pursue an international agenda!

\section{Summary}

Culture is the foundation of mental health and of everything we do in professional counseling. In the $21^{\text {st }}$ century, we face the challenge of deconstructing the science and practice of psychology that are indigenous to the Euro-American culture, and re-construct theories of mental health and counseling to serve the diverse cultural communities in the global world. For the common goal of promoting mental health worldwide and advancing the psychological science, international collaborative efforts are needed and professionals in the different corners of the world should share the responsibility. Equal power based international collaborations have to prevail the past one-directional international export/import to avoid harm and to achieve mutual benefit.

\section{Reference}

Adams G, Kurtiş T, Salter PS, Anderson SL (2012) A Cultural Psychology of Relationship: Decolonizing Science and Practice. In O Gillath, G Adams, AD Kunkel (Eds) Relationship Science: Integrating Evolutionary, Neuroscience, and Sociocultural Approaches, 49-70. Washington, DC: American Psychological Association.

American Psychological Association (1956) Division of Counseling Psychology, Committee on Definition. Counseling Psychology as a Specialty. American Psychologist 11, 282285.

Arnett J (2008) The Neglected 95\%: Why American Psychology needs to Become Less American. American Psychologist 63: 602-614.

Boughton JM (2002) Globalization and the silent revolution of the 1980s. Finance and Development 39 (1). Retrieved from https://bit.ly/2UDIJzm.

Buss DM (2001) Human Nature and Culture: An Evolutionary Psychological Perspective. Journal of Personality 69: 955-978.

Casas JM, Park YS, Cho B (2010) The Multicultural and Internationalization Counseling Psychology Movements: When all is said and done, it's all Multicultural, isn't it? In JG Ponterotto, JM Casas, LA Susuki, CM Alexander (Eds) Handbook of Multicultural Counseling, $3^{\text {rd }}$ ed., 189-200. Thousand Oaks, CA: Sage Publications, Inc.

Cheung FM, van de Vijver, FR, Leong FT (2011) Toward a New Approach to the Study of Personality in Culture. American Psychologist 66, 593-603. doi: 10.1037/a0022 389.

Christopher JC, Wendt DC, Marecek J, Goodman DM (2014) Critical Cultural Awareness: Contributions to a Globalizing Psychology. American Psychologist 69, 645-655.

Comas-Diaz L (2011) Multicultural Theories of Psychotherapy. In RJ Corsini, D Wedding (Eds) Current Psychotherapy, $9^{\text {th }}$ ed., 243-267. Belmont. CA: Brooks/Cole.

Committee of National Health and Family Planning (2016) 关于加强心理健康服务的指导意见,国卫疾控发 (2016) 77号). Retrieved from https://bit.ly/2Ga9Ai8.

Duan X, Duan C, Zhang H, Xie Y (2011) College Students' Expectations about 
Counseling in Inner Mongolia. China. Journal of Mental Health (in Chinese) 25: 577-582.

Duan C, Goodyearnn R (2015) When the West Meets the East in Counseling Psychology: A Two-way Street. Paper presented at the 4th Asia Pacific Rim International Counselling Conference, Wuhan, China, 6-8 November 2015.

Duan C, Hill C, Jiang G, Hu B, Lei Y, Chen J, Yu L (2014) The Use of Directives in Counseling in China: The Counselor Perspective. Counseling Psychology Quarterly 22: 442-457.

Duan C, Hill C, Jiang G, Hu B, Chui H, Hui K, Liu J (2012) Therapist Directives: Use and Outcomes in China. Psychotherapy Research : 442-457.

Engel J (2008) The rise of psychotherapy in the United States. New York, NY: Gotham Books.

Osnos E (2011) Meet Dr. Freud: Does Psychoanalysis have a Future in an Authoritarian State? New Yorker. Retrieved from https://bit.ly/2C6IEvz. [Accessed 10 January 2011].

Friedman TL (2006) The World is Flat: A Brief History of the Twenty-first Century. New York: Farrar, Straus and Giroux.

Ganesan M (2006) Psychosocial Response to Disasters--Some Concerns. Journal of International Review of Psychiatry 18: 241-247.

Geertz C (1973) The Interpretation of Cultures. New York: Basic Books.

Hardin EE, Robitschek C, Flores LY, Navarro RL, Ashton MW (2014) The Cultural Lens Approach to Evaluating Cultural Validity of Psychological Theory. Am Psychol. 69(7): 656-68.

Henrich J, Heine SJ, Norenzayan A (2010) The Weirdest People in the World? Behavioral and Brain Sciences 33(2/3): 1-23.

Hofstede G (2001) Culture's Consequences: Comparing Values, Behaviors, Institutions and Organizations across Nations $\left(2^{\text {nd }}\right.$ ed). Thousand Oaks, CA: Sage.

Jagger A (2002) Vulnerable Women and Neo-liberal Globalization: Debt Burdens Undermine Women' $\mathrm{S}$ Health in the Global South. Theoretical Medicine and Bioethics 23(6): $425-440$.

Jia X, Zen J (2014) Reflections and Exploration: Modern Psychotherapy in China. Beijing: Beijing Institute of Technology Press.

Jia X (2016) Psychoanalysis in China: Cultural Colonization or Culturally Fit? Neurological Disease and Mental Health 16: 377- 382.

Jiang G, Lin X, Duan C (2017) An examination of Chinese therapists' Being Directive and its Therapeutic Effect. A Paper Presented in C. Duan (Chair) Symposium: Reconstructuring and Localizing: Psychotherapy Practice in China. In 8th conference of World Congress of Psychotherapy, Paris, France. July, 2017.

Jorm AF (2012) Mental Health Literacy: Empowering the Community to take Action for better Mental Health. American Psychologist 67(3): 231-43.

Kitanaka J (2006) Society in Distress: The Psychiatric Production of Depression in Contemporary Japan. Doctoral dissertation, McGill University, Montreal, Quebec, Canada. Retrieved from https://bit.ly/2rzkxzQ.

Kleinman A, Eisenberg L, Good B (2006) Culture, Illness, and Care: Clinical Lessons from Anthropologic and Cross-cultural Research. Focus: The Journal of Lifelong Learning in Psychiatry IV, 140-149.

Lei Y (2016) The Chinese Mental Health Value Scale: Measuring Chinese College Students' Cultural Values, Values of Mental Health, and Subjective Well-being. Doctoral Dissertation, University of Kansas, Lawrence, KS. Retrieved from https:// bit.ly/2RRpFur.

Lei Y, Duan C (2015) Relationships among Chinese College Students' Defensive 
Pessimism, Cultural Values, and Psychological Health. Counselling Psychology Quarterly 29(4): 335-355.

Leung SA, Clawson T, Norsworthy KL, Tena A, Szilagyi A, Rogers J (2009) Internationalization of the Counseling Profession: An Indigenous Perspective. In LH Gerstein, PP Heppner, S Ægisdóttir, SA Leung, KL Norsworthy, International Handbook of Cross-Cultural Counseling: Cultural Assumptions and Practices Worldview, 111-124. Thousand Oaks CA, US: Sage Publications, Inc.

Li F (2015) Public's Views of Mental Illness in China: Content, Structure and Assessment. Doctoral Dissertation, Huazhong Normal University, Wuhan, China.

Link BG, Phelan JC (2001) Conceptualizing Stigma. Annual Review of Sociology 27: 363385.

Liu Y (2012) Exploring the Impacts of Cultural Globalization on Cultural Awareness/ values and English Writing in Chinese Content. Intercultural Communication Studies XXI(2): 94-110.

Lockett M (1988) Culture and the Problem of Chinese Management. Organization Studies 9: 475-96.

May R (1992) Forward. In J Kessler, SB Messer, DR Peterson, HH Strupp, PL Wachtel (Eds) History of Psychotherapy. Washington DC: APA

Markus HR, Kitayama S (1991) Culture and the Self: Implications for Cognition, Emotion, and Motivation. Psychological Review 98: 224-253.

Martin JK, Pescosolido BA, Olafsdottir S, McLeod JD (2007) The Construction of Fear: Americans' Preferences for Social Distance from Children and Adolescents with Mental Health Problems. Journal of Health and Social Behavior 48(1): 50-67.

Marsella AJ (1998) Toward a Global-community Psychology: Meeting the Needs of a Changing World. American Psychologists 53: 1282-1921.

McLellan B (1999) The Prostitution of Psychotherapy: A Feminist Critique. British Journal of Guidance and Counselling 27, 325-337. Retrieved from https://bit.ly/2C $8 \mathrm{TgKx}$.

Melluish S (2014) Globalization, Culture and Psychology, International Review of Psychiatry 26: 538-543.

Moghaddam FM, Erneling CE, Montero M, Lee N (2007) Toward a Conceptual Foundation for Global Psychology. In MJ Stevens, UP Gielen (Eds), Toward a Global Psychology: Theory, Research, Intervention, and Pedagogy, 179-206. New Jersey: Lawrence Erlbaum Associates Publishers.

Norsworthy KL, Heppner PP, Ægisdóttir S, Gerstein LH, Pedersen PB (2009) Exportation of U.S.-Based Models of Counseling and Counseling Psychology: A critical Analysis. In LH Gerstein, PP Heppner, S Ægisdóttir, SA Leung, KL Norsworthy (eds) International Handbook of Cross-Cultural Counseling: Cultural Assumptions and Practices Worldview, 69-88. Thousand Oaks: Sage.

Oyserman D, Lee SWS (2008) Does Culture Influence what and how we think?: Effects of Priming Individualism and Collectivism. Psychological Bulletin 134: 311-342.

Papadopoulos C, Foster J, Caldwell K (2012) Individualism-collectivism' as an Explanatory Device for Mental Illness Stigma. Community Ment Health 49(3): 27080.

Qian M, Smith CW, Chen Z and Xia G (2002) Psychotherapy in China: A Review of its History and Contemporary Directions. International Journal of Mental Health 30(4): 49-68.

Sedikides C, Brewer MB (2001) Individual, Relational, and Collective Self: Partners, Opponents, or Strangers? In C Sedikides, MB Brewer (Eds), Individual Self, Relational Self, Collective Self, 1-4. Philadelphia: Psychology.

Sedikides C, Gaertner L, O’Mara, EM (2011) Individual Self, Relational Self, Collective 
Self: Hierarchical Ordering of the Tripartite Self. Psychological Studies, 56(1): 98107. doi 10.1007/s12646-011-0059-0.

Shweder RA (1990) Ethical Relativism: Is There a Defensible Version? Ethos 18(2): 205218. Moral Relativism. Wiley on behalf of the American Anthropological Association.

Swartz L (1985) Anorexia Nervosa as a Culture-bound Syndrome. Social Science and Medicine 20: 725-730.

Tan CH (1990) Management Concepts and Chinese Culture. In J Child, M Lockett (Eds), Reform Policy and the Chinese Enterprise, vol. 1. Part A of Advances in Chinese Industrial Studies, 367. Greenwich, Conn. and London: JAI Press.

Tatlow DK (2010) Freudians put China on Couch. Retrieved from https://nyti.ms/2EtR 7eE. [Accessed 28 October 2010].

Thornicroft G, Brohan E, Kassam A, Holmes E (2008) Reducing Stigma and Discrimination: Candidate Interventions. International Journal of Mental Health System 2(3).

Triandis HC, Suh EM (2002) Cultural Influences on Personality. Annual Review of Psychology 53: 133-160.

Tyler JD, Clark JA, Olson D, Klapp DA, Cheloha RS (1983) Measuring Mental Health Values. Counseling and Values 27: 20-30.

Vogt L, Laher S (2009) The Five Factor Model of Personality and Individualism/ Collectivism in South Africa: An Exploratory Study. Psychology in Society 37: 3954.

Watters E (2010) Crazy like us: The Globalization of the American Psyche. New York: Free Press.

Xia X, Jiang G, Duan C (2015) Relationship among Attribution, Perceived Social Acceptance, and Helping Behavior among Chinese College Students. American Review of China Studies 16(1): 2015.

Yan HQ (1998) New Challenges of Psychiatry: The Development of Mental Health Service in Shanghai. Psychiatry and Clinical Neurosciences 52: 357-358.

Yang LH (2007) Application of Mental Illness Stigma Theory to Chinese Societies: Synthesis and New Directions. Singapore Medical Journal 48: 977-85. 
